US Army Corps

of Engineers $\mathrm{B}_{\circledast}$

Engineer Research and

Development Center

\title{
Computational Mechanics of the Paddlefish Rostrum
}

Guillermo A. Riveros, Felipe J. Acosta, Reena R. Patel, and Wayne Hodo
September 2021 
The U.S. Army Engineer Research and Development Center (ERDC) solves the nation's toughest engineering and environmental challenges. ERDC develops innovative solutions in civil and military engineering, geospatial sciences, water resources, and environmental sciences for the Army, the Department of Defense, civilian agencies, and our nation's public good. Find out more at www.erdc.usace.army.mil.

To search for other technical reports published by ERDC, visit the ERDC online library at https://erdclibrary.on.worldcat.org/discovery. 


\title{
Computational Mechanics of the Paddlefish Rostrum
}

\author{
Guillermo A. Riveros and Reena R. Patel \\ Information Technology Laboratory \\ U.S. Army Engineer Research and Development Center \\ 3909 Halls Ferry Road \\ Vicksburg, MS 39180 \\ Wayne Hodo \\ Geotechnical and Structures Laboratory \\ U.S. Army Engineer Research and Development Center \\ 3909 Halls Ferry Road \\ Vicksburg, MS 39180 \\ Felipe J. Acosta \\ Department of Civil Engineering and Surveying \\ University of Puerto Rico \\ Mayaguez, Puerto Rico
}

Final report

Approved for public release; distribution is unlimited.

Prepared for U.S. Army Corps of Engineers

Washington, DC 20314

Under Project Element 0601102, Project T22, "Research in Soil and Rock Mechanics," Task 01 


\section{Preface}

This study was conducted for and financial support was provided by U.S. Army Engineer Research and Development Center (ERDC) under PE 0601102, Project T22 "Research in Soil and Rock Mechanics," Task 01, and, also with support and resources from the ERDC Department of Defense Supercomputing Resource Center (ERDC DSRC) under the subproject of environmental quality modeling and simulation.

The work was performed by the Information Technology Laboratory (ERDC-ITL) and the Geotechnical and Structures Laboratory (ERDCGSL). At the time of publication of this paper, the Deputy Director of ERDC-ITL was Dr. Jackie S. Pettway and the Director was Dr. David Horner; the Deputy Director of ERDC-GSL was Mr. Charles W. Ertle II and the Direc-tor was Mr. Bartley P. Durst

This article was originally published in Engineering Computations on 9 December 2019.

The Commander of ERDC was COL Teresa A. Schlosser and the Director was Dr. David W. Pittman.

DISCLAIMER: The contents of this report are not to be used for advertising, publication, or promotional purposes. Citation of trade names does not constitute an official endorsement or approval of the use of such commercial products. All product names and trademarks cited are the property of their respective owners. The findings of this report are not to be construed as an official Department of the Army position unless so designated by other authorized documents. 


\title{
Computational mechanics of the paddlefish rostrum
}

\begin{abstract}
Purpose - The rostrum of a paddlefish provides hydrodynamic stability during feeding process in addition to detect the food using receptors that are randomly distributed in the rostrum. The exterior tissue of the rostrum covers the cartilage that surrounds the bones forming interlocking star shaped bones.

Design/methodology/approach - The aim of this work is to assess the mechanical behavior of four finite element models varying the type of formulation as follows: linear-reduced integration, linear-full integration, quadratic-reduced integration and quadratic-full integration. The paper also presents the load transfer mechanisms of the bone structure of the rostrum. The base material used in the study was steel with elastic-plastic behavior as a homogeneous material before applying materials properties that represents the behavior of bones, cartilages and tissues.

Findings - Conclusions are based on comparison among the four models. There is no significant difference between integration orders for similar type of elements. Quadratic-reduced integration formulation resulted in lower structural stiffness compared with linear formulation as seen by higher displacements and stresses than using linearly formulated elements. It is concluded that second-order elements with reduced integration are the alternative to analyze biological structures as they can better adapt to the complex natural contours and can model accurately stress concentrations and distributions without over stiffening their general response.

Originality/value - The use of advanced computational mechanics techniques to analyze the complex geometry and components of the paddlefish rostrum provides a viable avenue to gain fundamental understanding of the proper finite element formulation needed to successfully obtain the system behavior and hot spot locations.
\end{abstract}




\section{Introduction}

In nature, we find biological structures that have evolved for billions of years with extraordinary mechanical properties. Some examples of these structures are oyster shells, bones, fish scales, spider webs and paddlefish. Science has been interested in studying these systems to understand the relationships between light and highly resistant composite materials and develop alternative materials with similar properties (Flammang and Porter, 2011; Allison et al., 2013; Vepari and Kaplan, 2007). This work focuses on the paddlefish rostrum (Polydon spathula) and its behavior when under applied loads [Figure 1(a)].

Originally, the paddlefish's was thought to be used to dig for food from the mud or from seaweed (Forbes, 1878, 1888a, 1888b). Then, it was discovered that the paddlefish fed differently and that the rostrum had other functions. The paddlefish uses a random arrangement of electromagnetic sensors at the rostrum to detect plankton, its main food source. To feed the fish swims upstream with its mouth open, filtering plankton-rich water with its specialized gills. The paddle also provides stability while navigating, especially against the current (Hoover et al., 2013a, 2013b; Patel and Riveros, 2013; Allen and Riveros, 2013).

Previous research completed on the paddlefish rostrum has focused on the hydraulic, electromagnetic and mechanical properties of the fish's snout. The paddlefish's rostrum found to provide lift and stability to the fish during swimming and feeding. The sensitive electromagnetic properties of the rostrum allow the paddlefish to navigate and detect food. The rostrum also has impressive mechanical properties, such as extreme ductility and energy dissipation.

Allen and Riveros (2013) numerically studied the hydraulic lift and resistance characteristics of the rostrum as observed during the fish feeding process. The model, generated from a deceased young fish, used a turbulence model with experimentally based flow separation boundary conditions. The results showed that the support of the rostrum is comparable to that which occurs in asymmetrical air wing. However, friction and resistance losses reduced the lift benefit. Patel and Riveros (2013) modeled the rostrum fixed to a body representing an adult fish. The model provided a fundamental understanding of how the

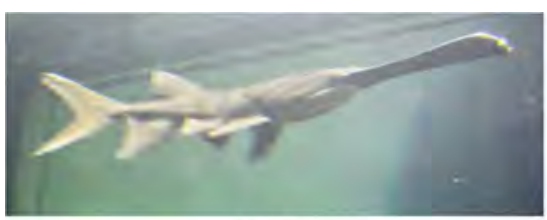

(a)

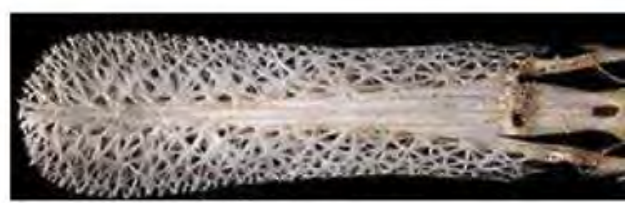

(b)
Figure 1. Paddlefish

Note: (a) Full Fish; (b) bone Structure of the paddle 
rostrum interacts with the rest of the body by providing greater hydraulic benefits. They evaluated 0, 5 and 10 degrees angles of attack when the fish was swimming against and along the flow direction. The study found that the rostrum generates thrust-like vortices that allow the fish to have propulsion and swim efficiently while it feeds, especially when swimming against the current. Additionally, the pressures generated in the mouth help the water and plankton to filter quickly and more efficiently.

A feature of the paddlefish snout is its ability to receive electromagnetic signals. The signal allows the paddlefish to detect the slight electromagnetic signals generated by the plankton. A study by Gurgens et al. (2000) evaluated the responses of 20 young fish to four types of obstacles: plastic, aluminum and aluminum covered with black plastic. The experiment used infrared illumination so that visual evasion would not affect it. They found that the fish avoided the aluminum obstacle in all the experiments, but collided several times with plastic and plastic covered aluminum, as well as with the tank walls. Wilkens et al. (2002) detailed the neurological system controlling the electromagnetic receptors by measuring the receptivity during the feeding process and the ability to avoid metallic obstacles. Wilkens and Hofmann (2007) tested the effects of obstructions to the paddlefish. The study concludes that the metallic structures used in the locks and dams affect the migratory pattern of the fish due to the generated electromagnetic emissions. Pothmann et al. (2012) established two types of neuron populations to process the information in the brain of the fish. In the study, they determined the functions and relations for processing received information between these two groups of neurons. The study concluded that these systems are complementary for detecting objects at different proximities and processing different sling amplitudes.

Due to the paddlefish's intricate lattice architecture cartilaginous system and combination of multiple materials, the rostrum has unique mechanical properties. Allison et al. (2013) evaluated mechanical properties and morphological content in several rostrums using nano indentation and Fourier transform infrared spectroscopy. The spectroscopy demonstrated that the main functional groups were amide, carboxylic, phosphate and carbonyl with no differences found between samples taken along the palate. The nano indentation provided the elastic modulus of the cartilage. The study discovered that the elastic modulus did not differ along the midline cartilage, but that there were differences in the bones along the outside lattice architecture. As part of the same study, a recent publication by Deang et al. (2017) presents an evaluation of the mechanical properties of the primary cartilage of the paddle. Due to soft cartilage being a hyperelastic material, they conducted tensile and compression experiments at different deformation ratios, from $0.01 / \mathrm{s}$ to $100 / \mathrm{s}$. They determined that Odgen hyperelastic model represents the constitutive behavior of the material, which was calibrated using the experimental data.

The paddle has a unique structure formed by skin that covers a network of hard cartilages intertwined in a grated structure of bones [Figure 1(b)]. This paddle acts as a cantilever beam, flat at the far end of the fish's mouth, thickening and narrowing as it approaches the mouth. Preliminary studies found that when comparing the ballistic attenuation capacity of a solid section to a rostrum section there was a dramatic reduction of energy due to the detailed structure of the hard cartilage (Riveros et al., 2014).

The finite element method (FEM) has been used to understand the structural response of bio-inspired structures. Flores-Johnson et al. (2015) conducted a numerical analysis of bioinspired, nacre-like composite plates. Flores-Johnson et al. (2014) and Knipprath et al. (2012) demonstrated that the hierarchical geometry of nacre, found in mollusk shells, spans over multiple length scales and displays superior mechanical characteristics. Flores-Johnson et al. (2015) found that under blast loading the nacre-like plates showed remarkable 
performance when compared to standard bulk plates. Tran et al. (2014) performed a numerical study to analyze the response of bioinspired composite plates based on nacre structures with underwater impulsive loading. Their study found that the damage spread over a larger area with a reduction in stress when composite structures were used. FEM was used by Snively et al. (2015) to study the bite force of the middle-to-late Eocene archaeocete Basilosaurusisis from Egypt. Their study found that the bite forces showed a negligible difference with the finite element formulation. Alam et al. (2016) studied the properties and architecture of the sperm whale skull amphitheater. The research reveals that the skull amphitheater is an elastic, flexible, triple-layered structure whose mechanical properties are conjointly channeled by bone histology and the properties of pore space. The study also concluded that the unique properties of the amphitheater have energy absorption characteristics while diving. Tsukrov et al. (2009) conducted a study to develop the numerical modeling tool to predict the impact forces on whales from ship strikes and its effect on their mortality risk. Jaw fracture was chosen as the fatal endpoint for whales hit by a vessel. The finite element model along with vessel-whale collision event model can be used for prediction for various ship strike scenarios.

The resulting physics based model in this study will enable the accurate examination of the underlying structure function relationships (architecture and material composition vs lightness and strength) of the rostrum. It will also allow the gain of fundamental insight into the design and engineering of high performance, lightweight, structured composites by examining the geometrical properties of the paddlefish nose, especially on the interfaces between hard cartilage and soft tissue.

The motivation behind this research effort is an earlier feasibility study that concluded that the non-uniform geometry of the rostrum is a natural toughening mechanism used to mitigate failure (Riveros et al. (2014). This work addresses the emerging need to develop new material designs that are strong, tough, lightweight and energy dissipative to rapidly support and protect the warfighter. Possible applications include protective panels, novel building materials, body and vehicle armor and ship design (Riveros et al. (2014).

The objective of this study is to develop a detailed FEM to evaluate the behavior of the paddlefish rostrum when using first- and second-order formulation elements with reduced and complete integration. The study's hypothesis is that reduced integration elements will require less computational time. Finally, the research also focuses on understating the state of stresses and deformations along the three zones (bone, cartilage and skin) and the influences of the materials in the transition boundary that will serve as the basis to study the mechanical behavior of the structure inside of the paddle.

\section{Evaluation of finite elements model}

A FEM was built and imported into the commercial program ABAQUS (Abaqus, 2014). The finite element model was developed based on a tomography of the fish snout. This was accomplished by performing computed tomography (CT) of several rostrums. CT scans were performed on the paddlefish rostrum using a General Electric Phoenix v $\mid$ tome $\mid \mathrm{x}$. Scans were done with an initial pixel resolution of $0.22 \mathrm{~mm}$. Figure 2 shows an example of a CT scan of the top portion of the rostrum. Note that denser materials are shown as darker colors in the CT scan, which allows the CT scan to differentiate between the midline cartilage, network cartilage and the matrix tissue (Figure 3). Multiple scans were taken of each section of the rostrum at different angles as the section underwent a complete rotation. Each section contained a total of 600 DICOM Images, which were then exported and stacked to create a three-dimensional model. The software Simpleware (Synopsys, 2017) was used to generate the finite element mesh of a rostrum section. 


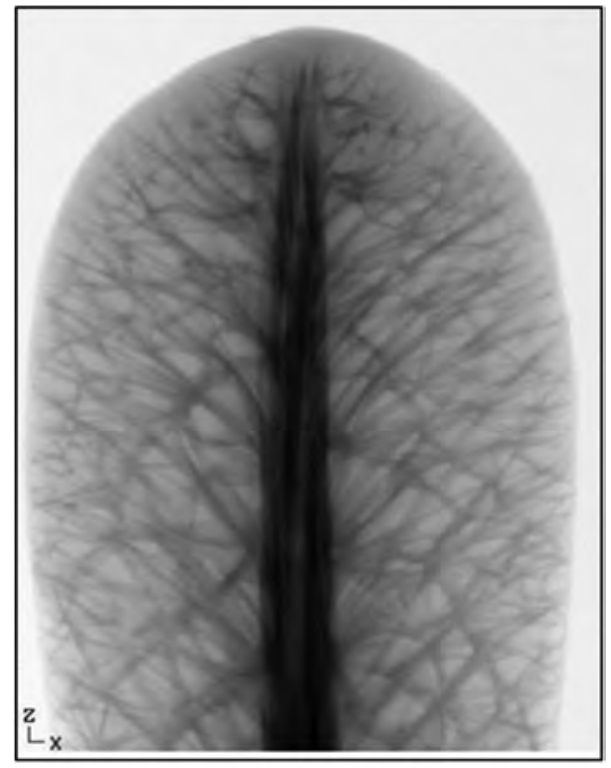

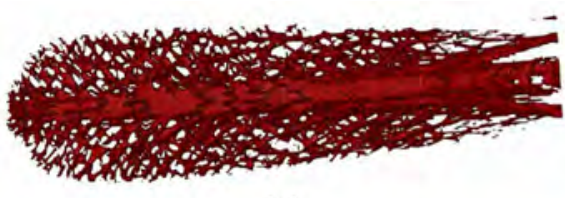

(a)

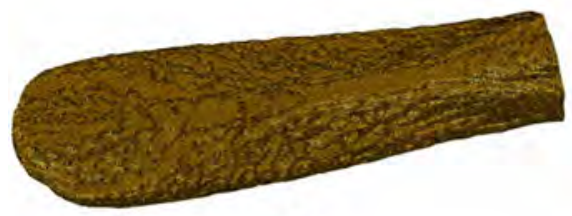

(c)

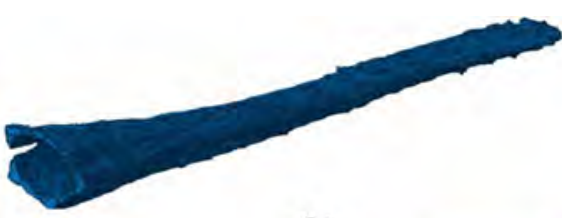

(b)

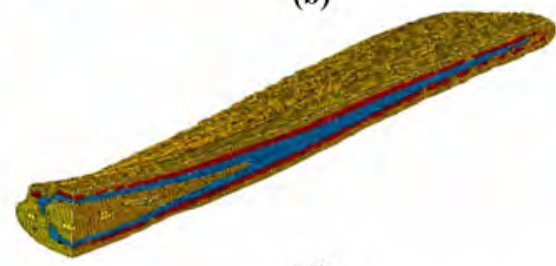

(d)

Notes: (a) primary cartilage; (b) secondary cartilage; (c) tissue; (d) integration of the mesh components

The longitudinal direction of the model is along the rostrum and parallel to the $z$-axis $(L=$ $275 \mathrm{~mm})$. The $x$-axis is horizontal, in the width direction of the rostrum, and the $y$-axis is parallel to the thickness (Figure 4$)(W=85 \mathrm{~mm})$. The rostrum thickness changes along the center bone from the mouth $(t=30 \mathrm{~mm})$ to the tip $(10 \mathrm{~mm})$, with similar changes in thickness from the center bone to the side edges of the rostrum. Figure 3 shows the finite element meshes of the three components of the rostrum. A combination of solid hexahedral and tetrahedral elements was used to mesh the rostrum. Tetrahedral elements were used due to the complex geometry of the paddlefish rostrum because they are the only elements that can 
mesh any $3 \mathrm{D}$ volume regardless of shape or topology. A disadvantage of the model is that the mesh is orphan limiting any reformulation. An orphan mesh is a mesh that has no geometry associated with it. However, the type of elements (linear or quadratic formulation) and the order of integration were modified for this study. Following these limitations, elements with different mathematical formulations were chosen for this model. Consequently, four models were evaluated, two with elements of linear formulation and two with quadratic formulation. The linear formulation models have 1,123,083 degrees of freedom, whereas quadratic models have 7,319,172 degrees of freedom. Only the hexahedron-type elements in the model allow the use of reduced or complete integration. The use of reduced integration allows for a shorter analysis time because the numerical integration of each term of the stiffness matrix is carried out with less iteration. However, the reduced integration has caused instabilities when used with first-order elements (Figure 5). In the case of pure bending, the displacement field has a bilinear approximation, which means that the strains vary linearly in the two directions. Nevertheless, the linear variation does not change along the length of the element; thus, the element cannot represent the curvature properly, developing a change in angle between the sides that allows the development of spurious shear stresses.

When a reduced integration is used, which translates into an integration point at the center of the element, it generates what is known as zero strain energy (Cook et al., 2002).

The displacement boundary conditions consisted of fixed edge conditions around the edges of the paddle and at the end of the mouth (narrow and thick part) $(\mathrm{Ux}=\mathrm{Uy}=\mathrm{Uz}=0$ )

Figure 4.

Reference of coordinate axes, loads and boundary conditions of the model

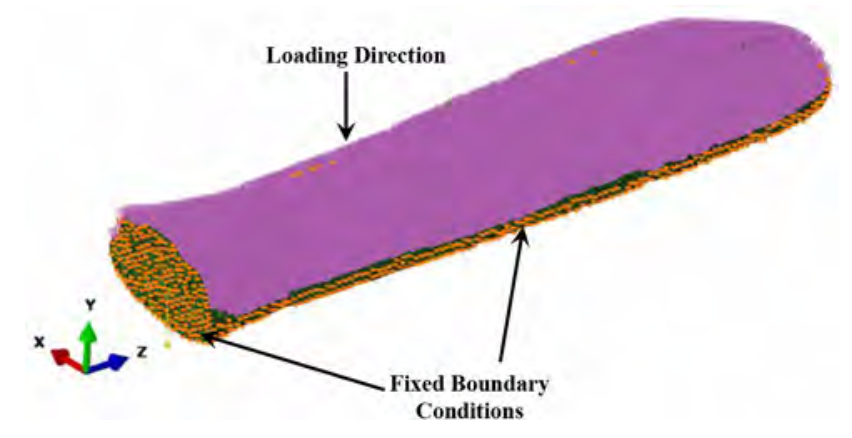

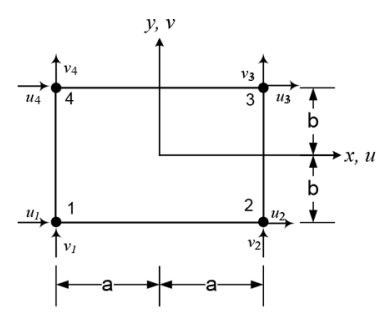

(a)

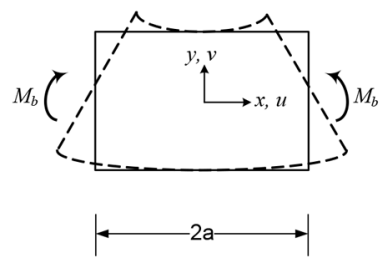

(b)
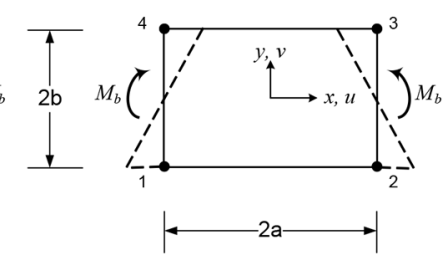

(c)
Figure 5.

Linear quadrilateral element
Notes: (a) General dimensions, numbering of nodes and degrees of freedom; (b) representation of bending in beams, (c) representation of displacement by finite elements (reproduced from cook et al., 2002) 
(Figure 4). The force boundary condition consisted of a normal uniform pressure of $25 \mathrm{MPa}$ (3.63 ksi) applied at the upper surface of the paddle (Figure 5). This condition is representative of the application of systems developed for energy attenuation.

Although the paddle is composed of different materials (hard and soft cartilages and tissue), only steel with elastoplastic properties was used to study the load transfer mechanism. Figure 6 shows the material constitutive model. The steel used has a modulus of elasticity of $200 \mathrm{GPa}(29,000 \mathrm{ksi})$, Poisson's ratio of 0.3 , a yield strength of $345 \mathrm{MPa}(50 \mathrm{ksi})$ and a yield strain of 0.172 per cent. The ultimate tensile stress of the material is $545 \mathrm{MPa}(79$ ksi). ABAQUS uses plastic curve in the form of true stress and true plastic strain (Abaqus, 2014). After reaching the yield stress, perfectly plastic behavior is undertaken. The density used is $7,850 \mathrm{~kg} / \mathrm{m}^{3}\left(490 \mathrm{lb} / \mathrm{ft}^{3}\right)$, which produces a net weight of $18.58 \mathrm{~N}(4.18 \mathrm{lbs})$.

The structural system was analyzed using a two-step general procedure. The first step included only the paddle's self-weight, then in the second step a uniform pressure was applied. The analysis also considers the geometric non-linearity of the problem by taking into account second-order deformations.

\section{Mesh convergence study}

A mesh convergence study was conducted for three models with 1.5, 3.0 and 5 million elements. The main purpose of the study was to determine the best mesh size required to ensure that the results are not affected by the mesh size. The rostrum was modeled as cantilever beam with $\mathrm{Ux}=\mathrm{Uy}=\mathrm{Uz}=0$ at a center line of the mouth end of the rostrum. All the other nodes at this location were restrained in the $Z-Z$ direction $(U z=0)$. The load boundary condition consisted of $2 \mathrm{KN}$ uniform pressure (Figure 7 ).

Figure 8 shows the number of elements in millions vs the maximum displacement for the node at the free end of the rostrum. Figure 8 also shows the minimum difference of the displacements for the linear and quadratic formulations analysis with full and reduced integration. The size of the elements in the 1.5 million elements model is $1 \mathrm{~mm}$ or smaller, in a rostrum that is about $280-\mathrm{mm}$ long and $80 \mathrm{~mm}$ in the wider, flat section. The element sizes in the other two models are smaller than that, about half the size for the 5 million models. It

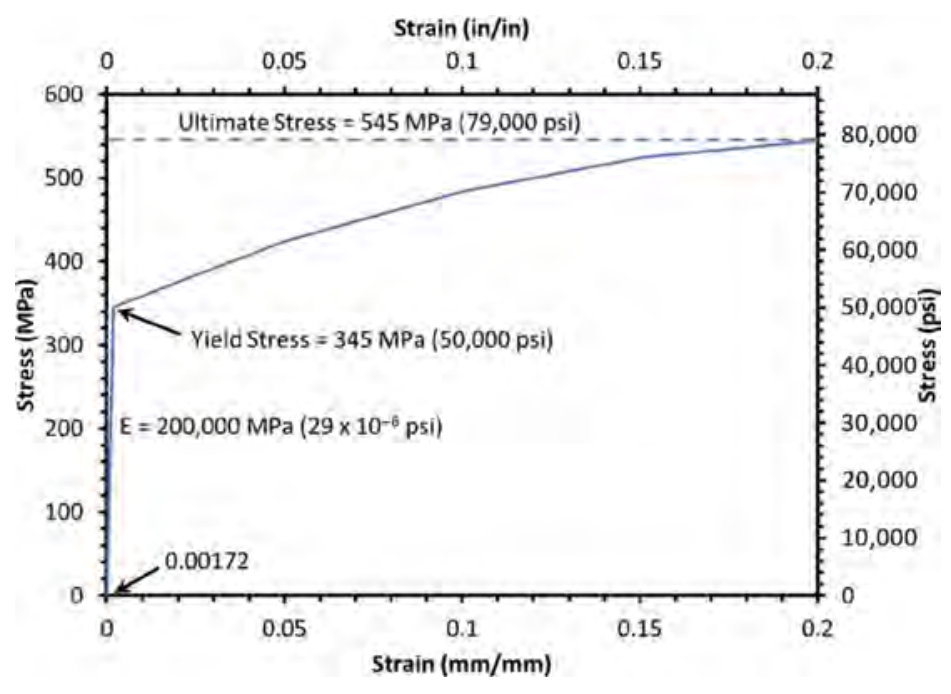

Figure 6. Curve of steel stressstrain 
is probable that in meshes with combination of elements, during refinements, the ratio of elements change, increasing the effects of element defects, that in instances that the models show signs of stiffening affecting the mesh convergence. This behavior is observed in the study by Liu and Glass (2013). The difference in displacement between the 3 and 5 million elements is only 7 per cent, but only 17 per cent with the 1.5 million models. Thus, the use of 1.5 million DOF is the proper number of elements for this study. It is important to note that the number of elements is dictated by the difficult challenging topography of the rostrum.

\section{Numerical model verification}

Verification efforts were focused on the overall model behavior of the rostrum described in the mesh sensitivity study. The displacement along the length of the rostrum was compared to the bioinspired model (Figure 9) described by Patel (2018). The bioinspired model was also modeled as a cantilever beam with $\mathrm{Ux}=\mathrm{Uy}=\mathrm{Uz}=0$ at a center line of the far end surface (representing the mouth end of the rostrum). All the other nodes at this location were

Figure 7.

Displacement and load boundary conditions of mesh sensitivity analysis
Figure 8.

Convergence study: Displacement vs number of elements in millions

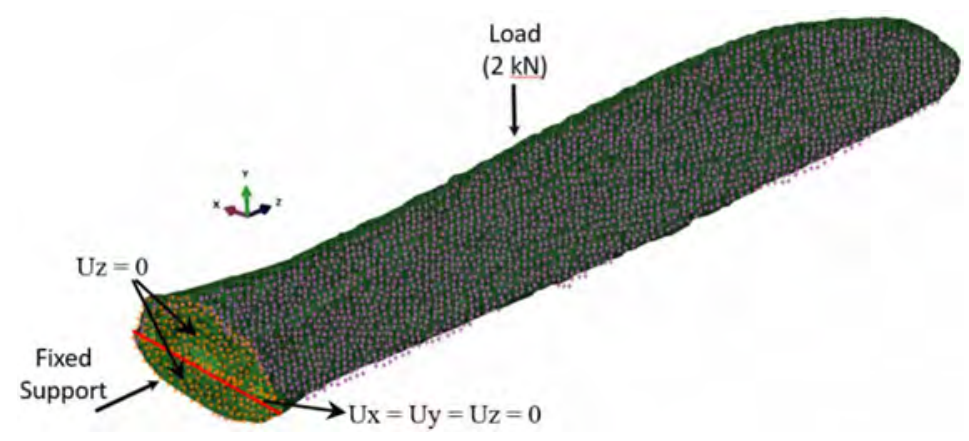

Convergence Study

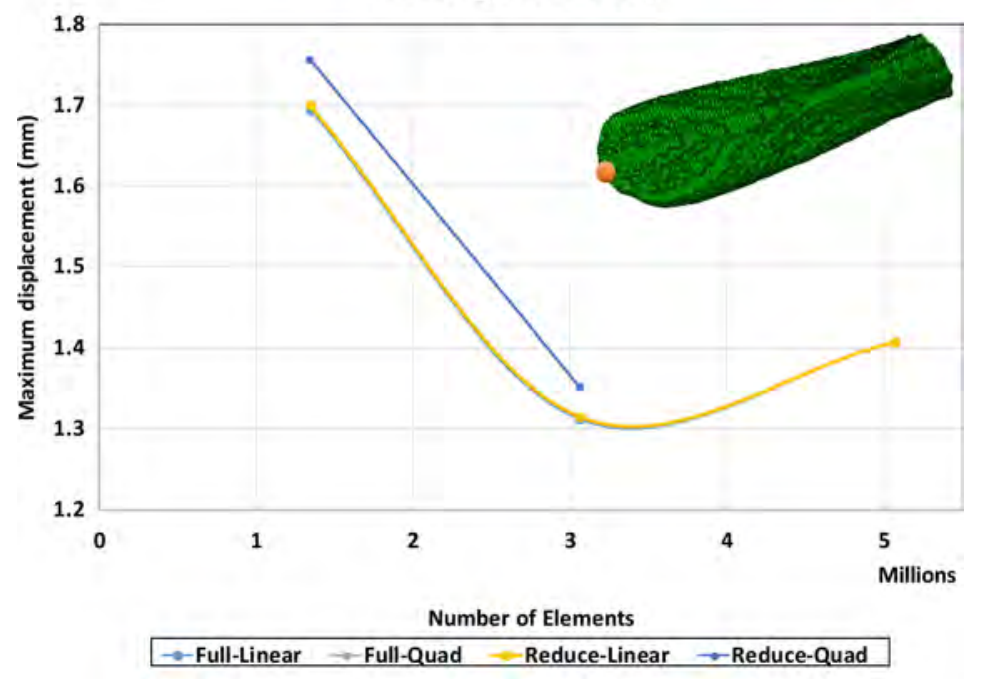



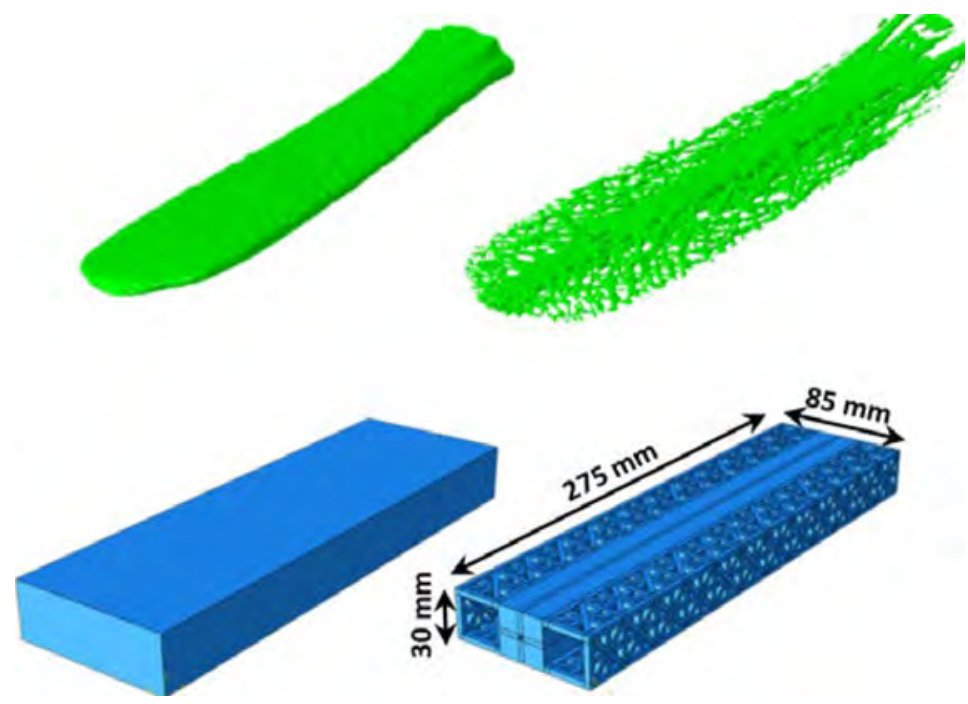

Figure 9.

Paddlefish rostrum and bioinspired models used for verification

restrained in the $\mathrm{Z}-\mathrm{Z}$ direction $(\mathrm{Uz}=0)$. The load boundary condition consisted of $75 \mathrm{KN}$ uniform pressure.

The bioinspired model has a larger cross section area along the length and width when compared to the rostrum (Figure 9). As described above, the rostrum thickness changes along the center bone from the mouth $(t=30 \mathrm{~mm})$ to the tip $(10 \mathrm{~mm})$, with similar changes in thickness from the center bone to the side edges of the rostrum. Therefore, the rostrum is more flexible than the bio inspired model.

The results of the numerical models used to verify the behavior of the paddlefish rostrum model are presented in Figure 10. Figure 10 shows that the bioinspired model has a similar displacement profile from the mouth to $120 \mathrm{~mm}$. From this point to the tip the higher stiffness of the bioinspired model produced 35 per cent less deformation than the rostrum. Despite the large difference in the tip deformation, it can be consider that both models have similar behavior.

\section{Mechanism of load transfer}

Displacement and yielding

The largest displacement in the normal direction of the rostrum ( $y$-axis) and the von Mises stress distribution were used to determine which of the four models is the most appropriate. The von Mises stresses were used to determine the yielding of the different components of the paddlefish snout. These stresses are equivalent tensile stresses derived from the stress deviator (Lubliner, 1990). Table I compares the maximum displacements obtained at different load levels in which each component of the rostrum began to experience yielding. Figure 11 shows a comparison of maximum displacements at each load increment for all the models of the rostrum. The difference in the behavior between reduced and complete integration formulations is very small, and the change is substantial between linear and quadratic formulation. The quadratic formulation induced higher flexibility in the model, producing 50 per cent more displacement compared with the linear formulation models. Meshes with elements of linear formulation converge at a lower ratio compared to meshes generated with quadratic formulation (Benzley et al., 1995; de Oliveira and Sundnes, 2016). 
Figure 10.

Paddlefish rostrum and bioinspired models vertical displacements

\section{Vertical Displacements of Rostrum and Bio-Inspired \\ Models}

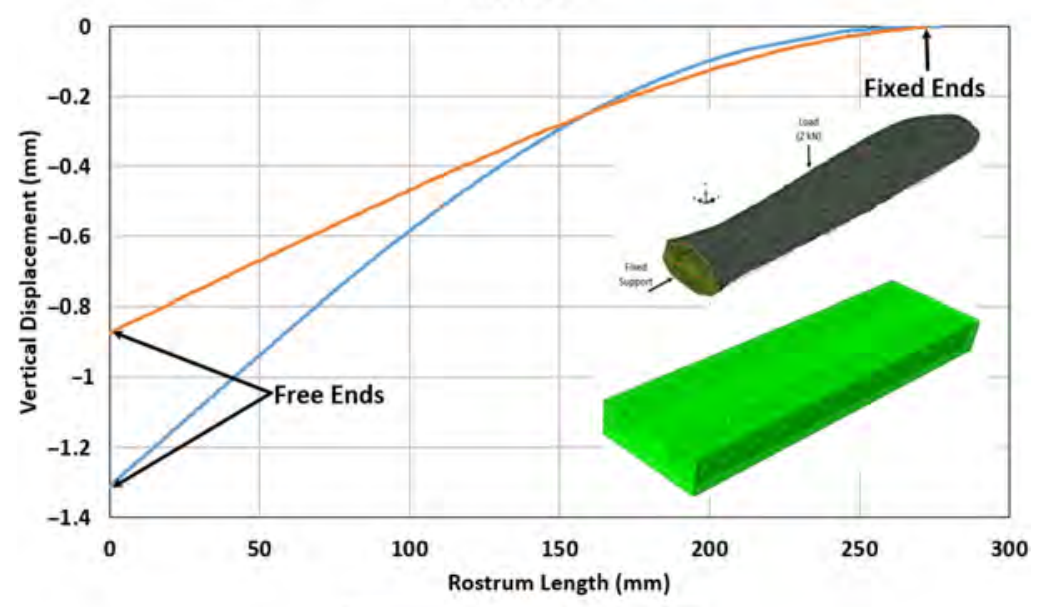

- Rostrum -Bio-Inspired

\begin{tabular}{|c|c|c|c|c|c|}
\hline Location & Variables & Linear reduce & $\begin{array}{l}\text { Linear } \\
\text { complete }\end{array}$ & $\begin{array}{l}\text { Quadratic } \\
\text { reduce }\end{array}$ & $\begin{array}{l}\text { Quadratic } \\
\text { complete }\end{array}$ \\
\hline \multirow[t]{2}{*}{ Tissue } & $\begin{array}{l}\text { Applied pressure, } \\
\mathrm{MPa}(\mathrm{ksi})\end{array}$ & $15.3(2.22)$ & $15.3(2.22)$ & $11.6(1.68)$ & $11.6(1.68)$ \\
\hline & $\begin{array}{l}\text { Displacement, mm } \\
\text { (in } \times 10^{-3} \text { ) }\end{array}$ & $0.2031(8.0)$ & $0.2004(7.89)$ & 0.1607 (6.33) & 0.1595 (6.28) \\
\hline \multirow[t]{2}{*}{$\begin{array}{l}\text { Primary } \\
\text { cartilage }\end{array}$} & $\begin{array}{l}\text { Applied pressure, } \\
\mathrm{MPa}(\mathrm{ksi})\end{array}$ & $20.3(2.94)$ & $20.3(2.94)$ & $16.6(2.41)$ & $16.6(2.41)$ \\
\hline & $\begin{array}{l}\text { Displacement, mm } \\
\text { (in. } \times 10^{-3} \text { ) }\end{array}$ & 0.3289 (12.95) & 0.3236 (12.74) & $0.2795(11.00)$ & $0.2765(10.89)$ \\
\hline \multirow[t]{2}{*}{$\begin{array}{l}\text { Secondary } \\
\text { cartilage }\end{array}$} & $\begin{array}{l}\text { Applied pressure, } \\
\mathrm{MPa} \text { (ksi) }\end{array}$ & $25(3.63)$ & $25.0(3.63)$ & $24.1(3.06)$ & $24.1(3.06)$ \\
\hline & $\begin{array}{l}\text { Displacement, mm } \\
\text { (in. } \times 10^{-3} \text { ) }\end{array}$ & $0.6404(25.21)$ & $0.6234(24.54)$ & $0.9918(39.05)$ & $0.9577(37.70)$ \\
\hline \multicolumn{2}{|c|}{$\begin{array}{l}\text { Maximum displacement, } \mathrm{mm} \\
\text { (in. } \mathrm{x} 10^{-3} \text { ) }\end{array}$} & $0.6404(25.21)$ & $0.6234(24.54)$ & $1.2540(49.02)$ & $1.206(47.48)$ \\
\hline
\end{tabular}

Figures 12 and 13 shows a comparison of contour plots of von Mises stresses at the three loading stages based on values given in Table I for the first-order and second-order models with reduced and full integration. The gray color represents those elements that have reached and exceeded the yield strength of $345 \mathrm{MPa}(50 \mathrm{ksi})$. The majority of the yielding is experienced in front of the paddle, whereas in the narrow but thick part (closer to the mouth of the fish) the stresses are below the yield stress indicating a higher stiffness in this area. The central bone expanding from the center to the ends provides the observed rigidity. Additionally, the model with quadratic formulation reaches yielding at a load level lower than the linear formulation model, due to the flexibility typically demonstrated in these 


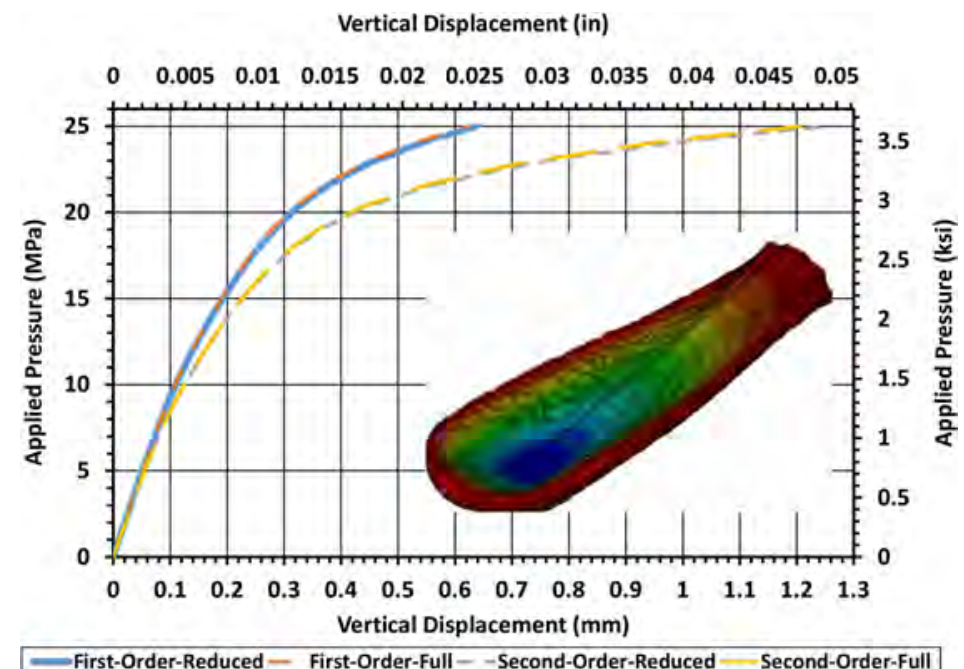

elements. For cases with high geometric nonlinearities and complicated geometry, elements with a quadratic formulation have shown better performance than those with a linear formulation (Hughes and Belytschko, 2002).

Based on the previously stated results, quadratic with reduced integration is the optimal formulation. The difference is not substantial between complete and reduced integration because only the $3 \mathrm{D}$ hexahedron elements have the option of selecting the integration order and they represent only 8 per cent of the elements of the entire mesh. The rest of the elements are tetrahedrons, whose formulation is with complete integration.

To evaluate the general behavior in the paddle, paths were drawn at the top and bottom of the center bone, the top and bottom along the side containing the interfaces of the three different parts and where the maximum deformation and stresses are located. Figure 14 shows the three paths. Path $A$ crosses the rostrum width (parallel to the $x$-axis) close to the location where the maximum displacement occurs. Paths $\boldsymbol{B}$ and $\boldsymbol{C}$ are along the length of the rostrum (parallel to the $\boldsymbol{z}$-axis), where $\boldsymbol{B}$ is at the center of the vane and $\boldsymbol{C}$ is offset $20 \mathrm{~mm}$ $(0.787$ in) from $\boldsymbol{B}$. In turn, paths were traced in the upper surface, in the inner section and in the lower surface of the rostrum as shown by the red lines in Figure 15.

Figure 16 shows the von Mises stresses along the paths for an applied pressure where the maximum levels of yielding are observed (24.1 MPa). The stresses at the edges are much higher because of the displacement boundary conditions. Figure 14(a) (Path $\boldsymbol{A}$ of Figure 15) shows an increase of stresses at the top and bottom as the path moves to the center from the edge of the rostrum. However, at the center path the stresses are relatively low because of the proximity of the center path to the neutral axis. The rostrum is stiff at the center of the path because of the center bone's increased stiffness. The increased stiffness is due to the higher separation between the two parts of the bone and the higher moment of inertia. At the edges the section is much thinner $(10 \mathrm{~mm})$ [Figure 2(d)] behaving similar to a thick shell that exhibits flexural and membrane actions. Towards the center, the behavior is more plate like and from the stresses it can be observed that the rostrum is symmetric along the $x$-axis. However, as the load increases, the stress distribution starts to lose its symmetry. Figure 16(b) shows that at a distance of about $115 \mathrm{~mm}$ from the left side, the stresses along the longitudinal axis are at yielding. Then the values 


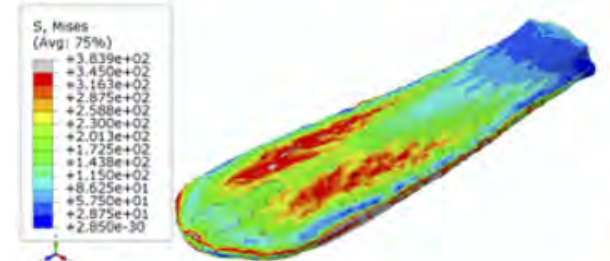

(a)

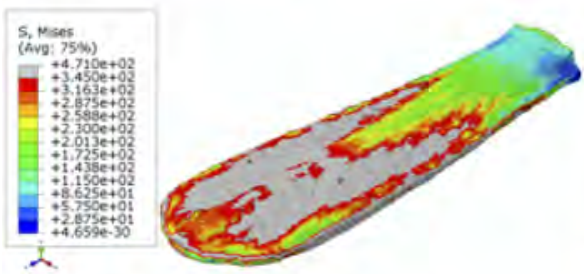

(c)

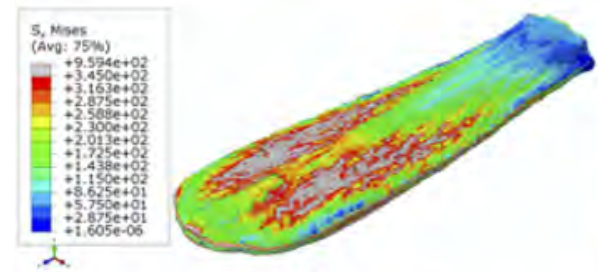

(e)

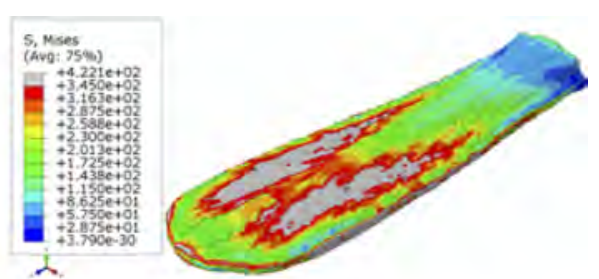

(b)

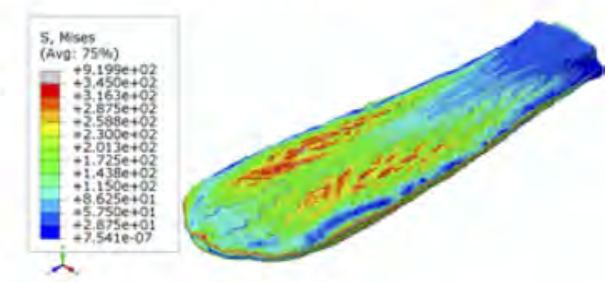

(d)
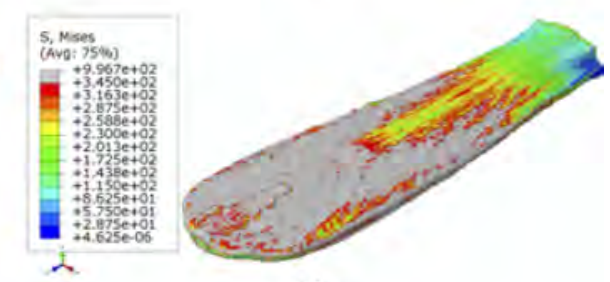

(f) c) and second-orderreduced integration (d, e and f). Yielding regions are depicted in grey

Notes: (a) First-order-reduced: 15.3 MPa (2.22 ksi); (b) first-order-reduced: $20.3 \mathrm{MPa}$ (2.94 ksi); (c) first-order-reduced: $25 \mathrm{MPa}(3.63 \mathrm{ksi})$; (d) second-order-reduced: $11.6 \mathrm{MPa}$ (1.68 ksi); (e) second-order-reduced: 16.6 MPa (2.41 ksi); (f) second-order-reduced: $24.1 \mathrm{MPa}$ (3.06 ksi)

drop below yielding, reaching a minimum value at a distance between 135 and $140 \mathrm{~mm}$. The stresses increase again to a peak at $200 \mathrm{~mm}$. Figure 16(c) shows the stresses in the paths parallel to the $z$-axis of the rostrum $20 \mathrm{~mm}$ from Path $\boldsymbol{B}$. They begin in the wide and thin free zone of the snout and end where it sticks to the narrow but thick mouth of the fish, with greater rigidity. We can appreciate that in the Path $\boldsymbol{B}$, central part, the stresses are smaller than away from the central part (Path $\mathbf{C}$ ), which passes through the thinnest area of the rostrum. All the graphs demonstrate that the path inside the section maintains low stress values, as it is close to the neutral axis of the blade. The magnitude of the stresses does not change significantly with the increase in pressure for the upper and lower section; even though, the strength limit has been reached and exceeded and the material displays deformation hardening. This behavior indicates that the section is partially plasticized and its deformation does not reach a significant stress change.

Stress distributions through thickness and cartilages

To evaluate stress distributions through the thickness with respect to the applied pressure, a cross-section at the flat part of the rostrum was selected. Stresses evaluated include von 


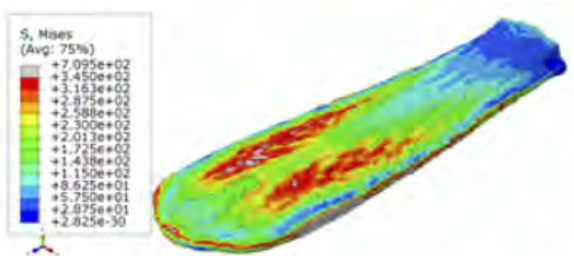

(a)

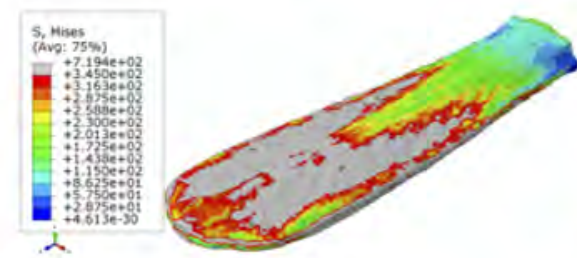

(c)

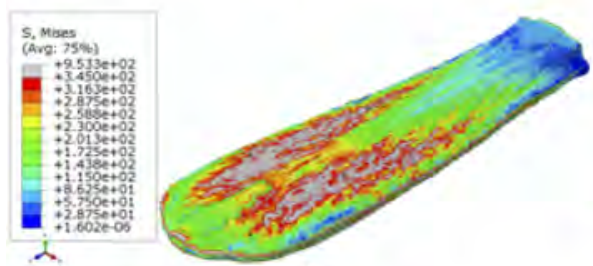

(e)

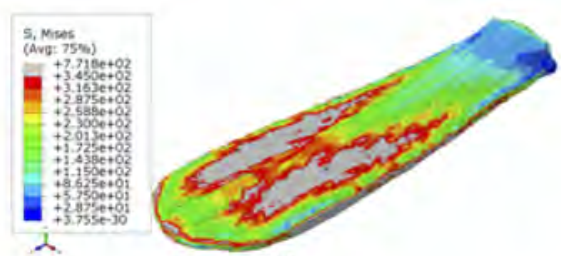

(b)

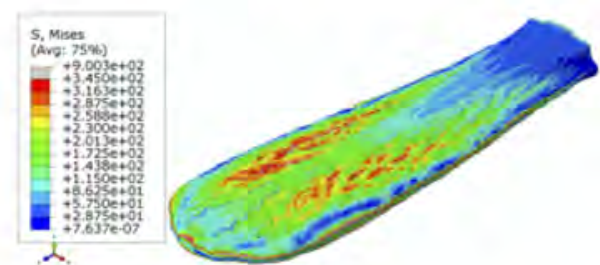

(d)

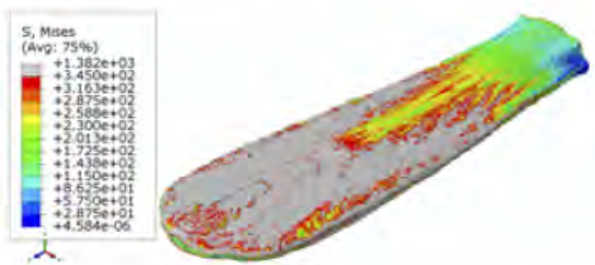

(f)

Notes: (a) First-order-full: 15.3 MPa (2.22 ksi); (b) first-order-full: $20.3 \mathrm{MPa}(2.94 \mathrm{ksi})$;

(c) first-order-full: $25 \mathrm{MPa}$ (3.63 ksi);(d); second-order-full: $11.6 \mathrm{MPa}(1.68 \mathrm{ksi})$;

(e) second-order-full: 16.6 MPa (2.41 ksi); (f) second-order-full: $24.1 \mathrm{MPa}(3.06 \mathrm{ksi})$

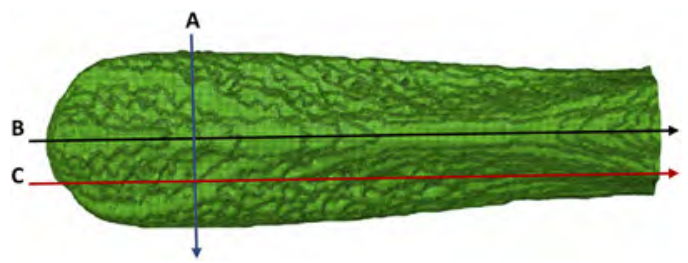

Figure 14.

Location of paths for extraction of von

Mises stresses

Mises, $\sigma_{X}$ (global $x$-axis), $\sigma_{Z}$ (global $z$-axis) and $\sigma_{X}^{\prime}$ (local $x$-axis). Vertical paths that cross each zone were defined and nodes in key locations. Likewise, stresses were evaluated at the center of the rostrum where the three main rostrum components pass. References of these locations are shown in Figure 17(a-c), where only the primary cartilage is depicted in (a) and (b). Figure 17 (a) includes the location of the cut used to evaluate stresses near the location of maximum displacement at the wider cross-section of the rostrum. This cut line also passes through a cartilage joint (Point A) to study how the stresses are distributed through stellate cartilages. Stresses of these locations used the global reference axes shown in Figure 17(a). 

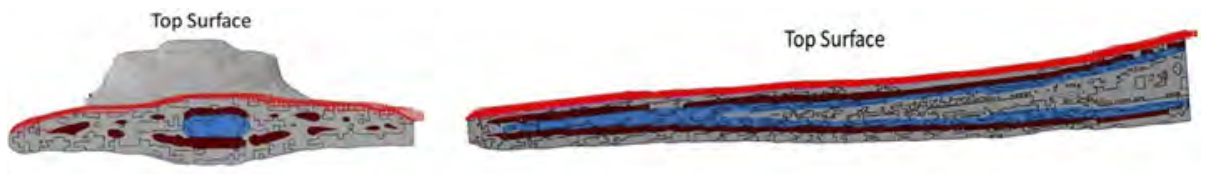

Figure 15.

Paths location

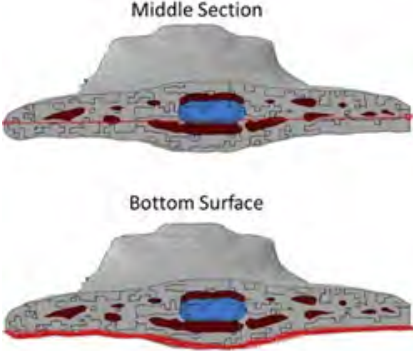

(a)

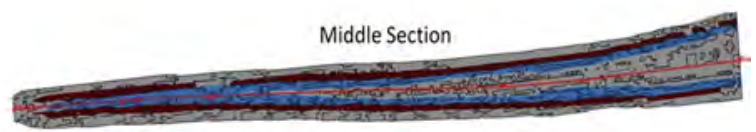

Bottom Surface

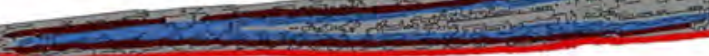

(b)

Notes: (a) Width of the paddle; (b) along the paddle. (Refer to Figure 12)

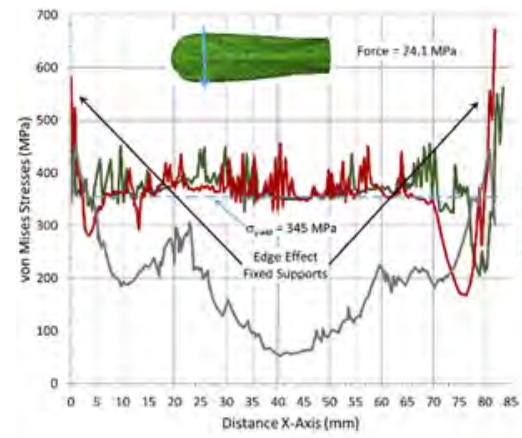

(a)

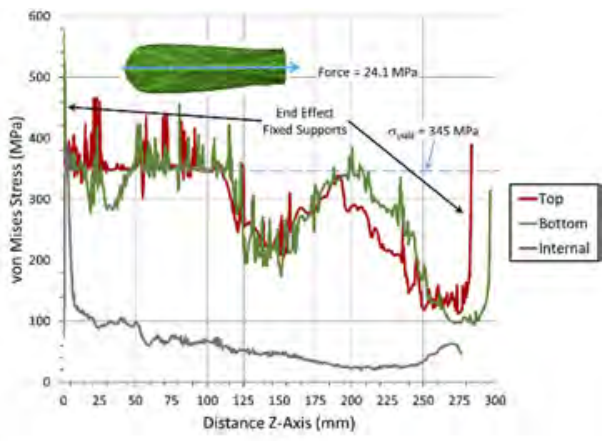

(b)
Figure 16.

von Mises stresses along the paths for quadratic-reduced formulation model for an applied pressure of 24.1 MPa (3.06 ksi)
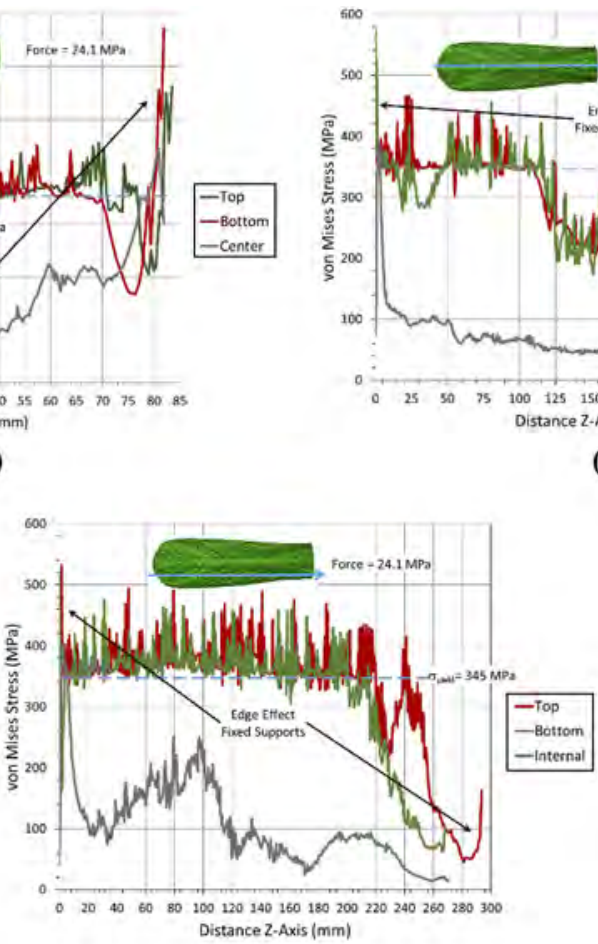

(c) 


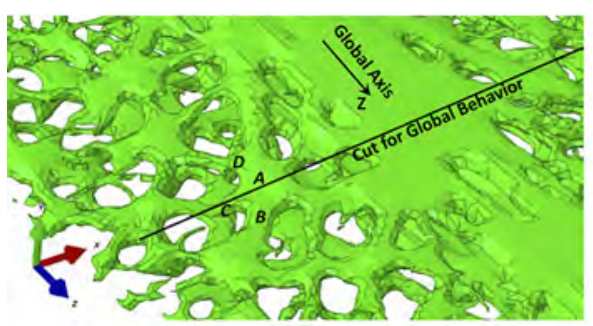

(a)

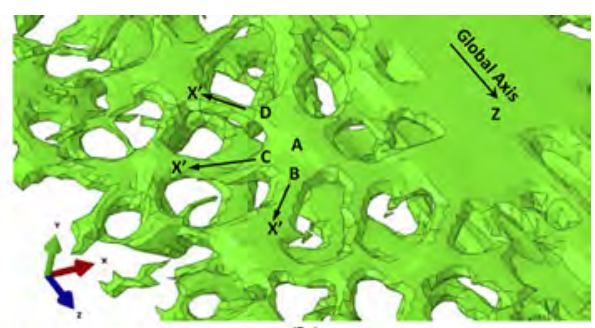

(b)

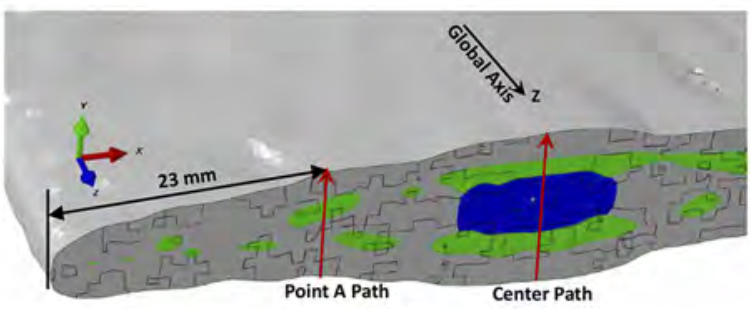

(c)

Notes: (a) Transverse cut and cartilage labels; (b) reference local axes and cartilage labels; (c) through the thickness

These cartilages named B through D, are connected at A. Stresses at these locations were evaluated using a local axis indicated in Figure 17(b). Most of the vertical paths crossed only one cartilage. However, paths through cartilages D crossed a bottom cartilage and allowed to find the interaction between them.

\section{Centre of rostrum}

Figure 18 illustrates the cross-section of the rostrum at the center where all three components are located (tissue - green, primary cartilage - red and secondary cartilage blue). The location of the vertical path is shown in Figure 18. This path starts at the bottom of the rostrum ( $y$-axis) and ends at the top surface. The figure also shows the place of the nodes used to extract stresses as a function of the demand. The location of these nodes is close to the path, but they are not necessarily on it. These nodes are strategically picked to record stresses at key points. N-1 and N-14 are in the tissue. $\mathrm{N}-2$ and $\mathrm{N}-13$ are at the interface

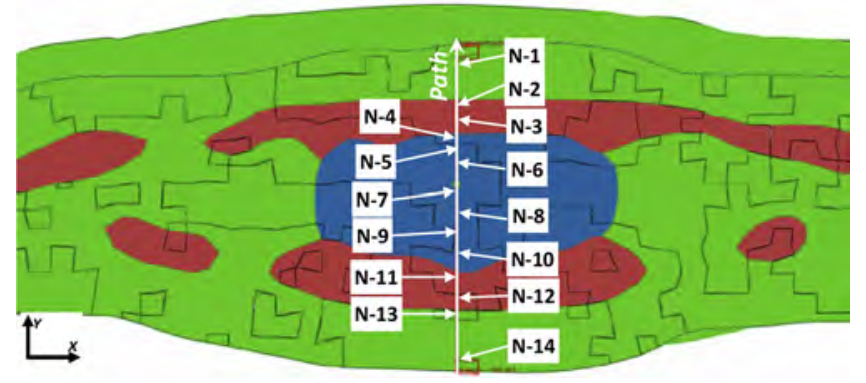

Figure 18.

Illustration of the vertical path and node location for the center portion of the rostrum (green tissue, red-primary cartilage, blue secondary cartilage) 
of tissue and primary cartilage. N-4 and N-11 are at the interface of primary and secondary cartilages. N-5 through N-10 is inside the secondary cartilage. Finally, N-3 and N-12 are inside the primary cartilage. At this position, the thickness of the rostrum is near $15 \mathrm{~mm}$ (0.60 in).

Figures 19 and 20(a) and (b) show von Mises, $\sigma_{Z}$ (global $z$-axis) and $\sigma_{x}$ (global $x$-axis) stresses for the selected nodes through the thickness indicated in Figure 18. The stresses are varying as a function of the applied pressure. Yield stress is marked in each figure for reference purposes. Also, the applied pressure at which yielding starts (elastoplastic behavior) is indicated in the horizontal axis. Based on the von Mises stresses and the node location with respect to the section, $\mathrm{N}-1, \mathrm{~N}-2, \mathrm{~N}-13$ and $\mathrm{N}-14$ are experiencing stress values at yielding at applied pressures between 23 and $24 \mathrm{MPa}$, but N-2, N-13 and N-14 are reaching yielding at the maximum applied pressure of $25 \mathrm{MPa}$ (Figure 19). As stresses reach and pass the yield point, their rate of change with distance is reduced with change in pressure. The figure also shows that N-3 and N-12 are just below yielding. It means that at the maximum applied pressure, the tissue and the primary cartilage regions are experiencing yielding (Figure 19).

Positive stresses in Figure 20 are from the nodes located below the centroid of the rostrum at the tension side and negative stresses are for nodes located above the centroid at

Figure 19.

Variation of von Mises stresses at selected nodes with applied pressure at the center of the rostrum for the second-orderreduced integration model. (Reference in Figure 16)
Figure 20.

Variation of stresses (a) along the $z$ - and (b) along the $x$-axes at selected nodes with applied pressure at the center of the rostrum for the second-orderreduced integration model (reference in Figure 16)

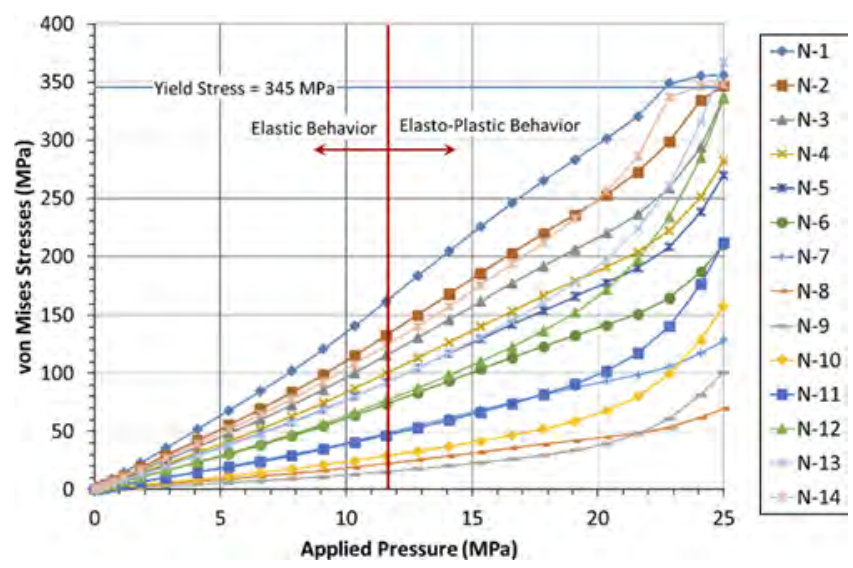

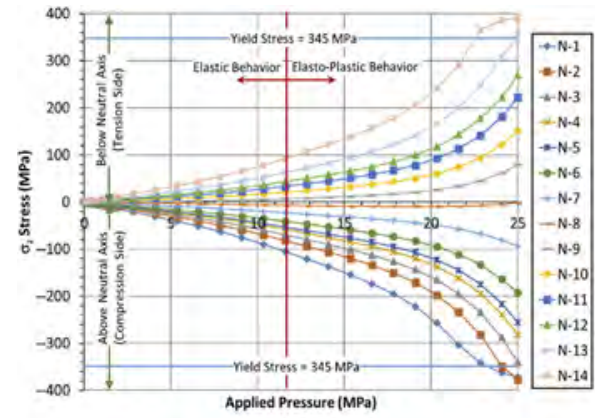

(a)

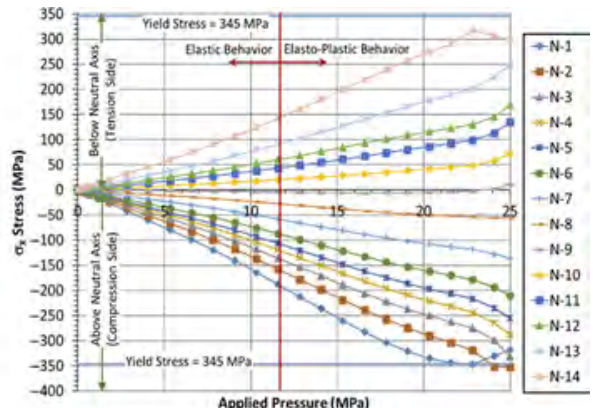

(b) 
the compression side. Figure 20(a) show that nodes N-1, N-2, N-3, N-13 and N-14 are at yielding. However, stresses along the $x$-axis in Figure 20(b), only N-1 and N-2 are at yielding stresses. This means that what is dominating the yield surface is the stresses along the global z-axis or the longitudinal stresses, where the section is stiffer. In Figure 20(a) and (b), it is also noticed that N-8 is at the neutral axis for $\sigma_{Z}$, whereas N-9 is at the neutral surface for $\sigma_{X}$. However, their corresponding von Mises stresses (Figure 19) are very close to each other and they crossed as reaching the maximum applied pressure. This crossing can be attributed to the redistribution of stresses. In Figure 20(b), stresses for N-9 change from negative to positive at the maximum applied pressure. In Figures 19 and 20, all the stress curves are linearly varying with the applied pressure until the material and the geometrical nonlinearity start to occur. Then, the stresses start to redistribute to the other regions of the section that are in the elastic zone. Evidence of this behavior is observed by the larger rate of increment that occurs to the stress diagrams. This is occurring after an applied pressure of $20 \mathrm{MPa}$. Excessive deformation of a fixed flat structure not only exhibit flexural stresses but also it has a degree of membrane action. The behavior exhibited by the rostrum depicted in these figures is similar to a two-way slab.

\section{Point a}

Figure 21 presents a cut of the rostrum at Point A shown in Figure 17. This section cut includes only tissue (green color) and primary cartilage (red color). This section is thinner and less stiff than the center of the rostrum. It is in a zone where most of the yielding occurs. The figure shows the location of the vertical path used to extract stresses as a function of the vertical location through the thickness. The nodes in Figure 21 are strategically picked to record stresses at key points. N-1, N-5 and N-6 are in the tissue. N-2 and N-4 are at the interface of tissue and primary cartilage. Finally, N-3 is inside the primary cartilage. At this location, the thickness of the rostrum is near $10.6 \mathrm{~mm}$ ( $0.42 \mathrm{in}$.).

Figure 22 and Figure 23(a) and (b) show von Mises, $\sigma_{Z}$ (global $z$-axis) and $\sigma_{X}$ (global $x$-axis) stresses for selected nodes through the thickness indicated in Figure 21 . It is observed in Figure 22 that based on the von Mises stresses and the location of the nodes along the section that N-1 (at the tissue) starts to yield after the applied pressure of $15 \mathrm{MPa}(2.17 \mathrm{ksi})$. It is also observed that nodes $\mathrm{N}-2$ and $\mathrm{N}-6$, which are located almost equidistant from the neutral axis, start to yield after the applied pressure of $17.5 \mathrm{MPa}$ (2.53 ksi). Node N-3 starts to yield at $19 \mathrm{MPa}$ and N-4 after $20 \mathrm{MPa}(2.90 \mathrm{ksi})$. Node N-5, which is near the neutral axis, is close to yielding at the maximum applied pressure of $25 \mathrm{MPa}(3.63 \mathrm{ksi})$. Figure 23(a) and (b) gave a better indication on the stress distributions

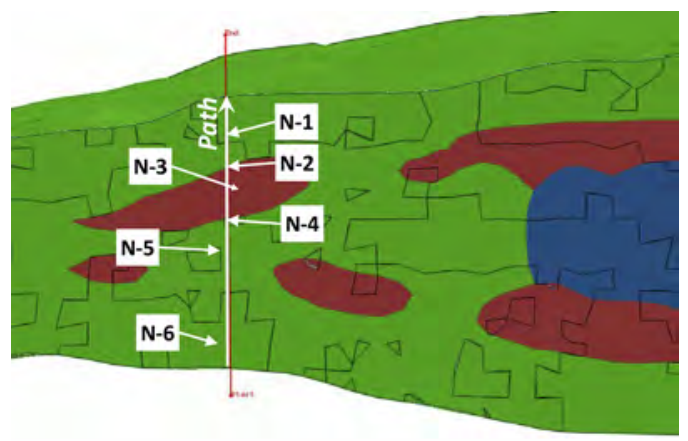

Figure 21 . Illustration of the vertical path and node location for point A (Figure 12). (green - tissue, red primary cartilage, blue-secondary cartilage) 
to each of the axes and their contribution to the section yielding pattern. In both figures, it is observed that $\mathrm{N}-1$ through $\mathrm{N}-5$ is above the neutral axis of the section, with N-5 very close to the neutral surface. As opposed to the central cut which is very stiff along the $z$ axis, at this point the behavior is dominated by bending along the $x$-axis $\left(\sigma_{X}\right)$, demonstrated by the same yielding patterns of at the nodes that concur with values observed in Figure 22. None of the stresses along the $z$-axis reached yielding. From Figure 23(a), it is observed that N-5 has a very low stress value on the negative side (compression) up to the point in which the section starts to experience significant yielding after $19 \mathrm{MPa}(2.76 \mathrm{ksi})$, and its values start to increase due to the stress redistributions. Similar to von Mises stresses, the values for N-5 are at yielding at the maximum applied pressure.

\section{Cartilages branching from point a}

This section discusses results obtained from nodes located at the cartilages that are branching from the cartilage joint referred to as point A in Figure 17(a) and (b). The crosssection at the location of the paths using the reference of the local axis (parallel to each cartilage referred as local $x$-axis) at each point is shown in Figure 24. Each section illustration has a path through the thickness, the number and location of each node used to extract the stresses as a function of the applied pressure and reference to the global

Figure 22.

Variation of von Mises stresses at selected nodes with applied pressure at point $\mathrm{A}$ of the rostrum for the second-orderreduced integration model. (Reference in Figure 19)

Figure 23.

Variation of stresses (a) along the $z$ - and (b) along the $x$-axes at selected nodes with applied pressure at point $A$ of the rostrum for the second-orderreduced integration model (reference in Figure 19)

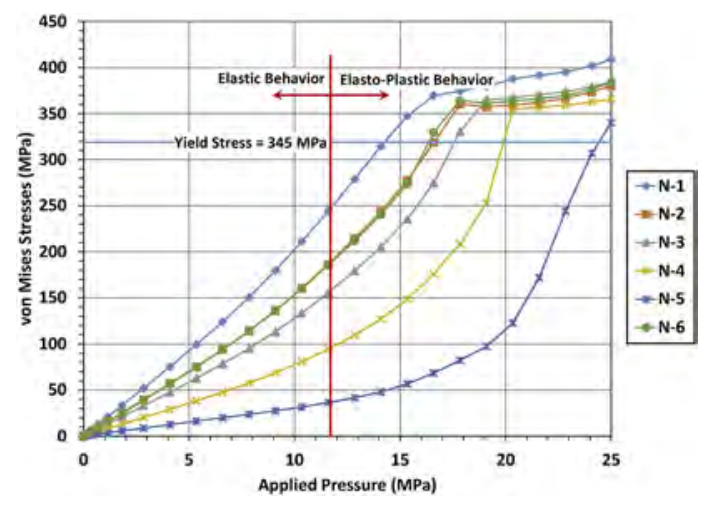

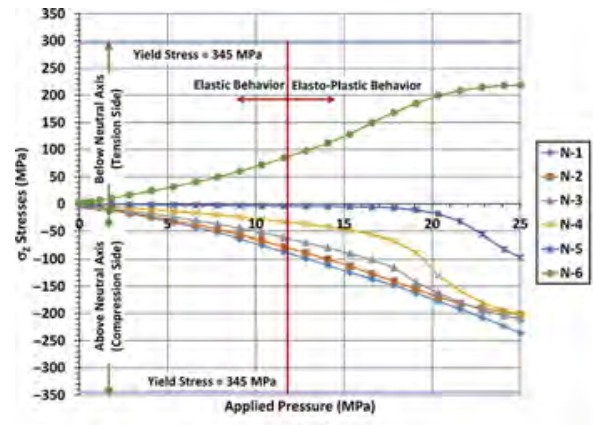

(a)

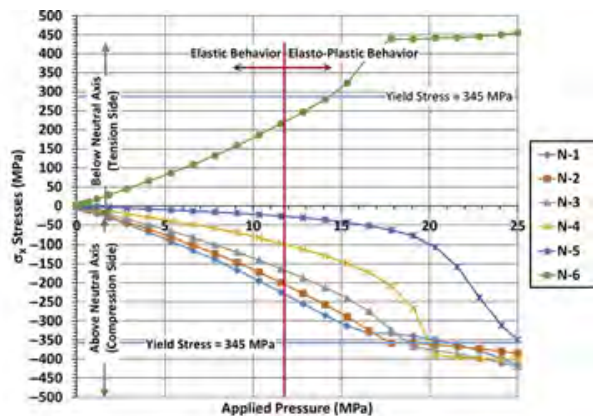

(b) 


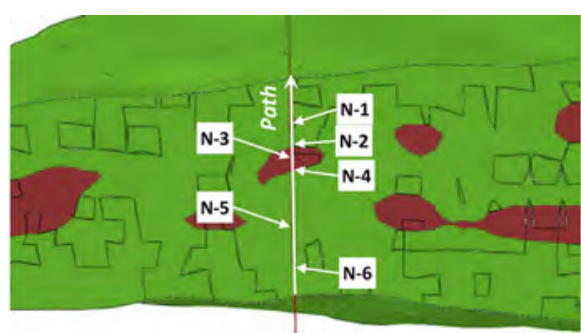

(a)

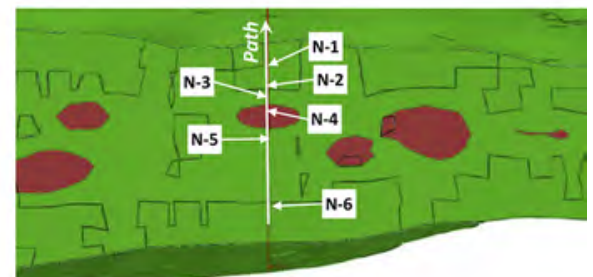

(b)

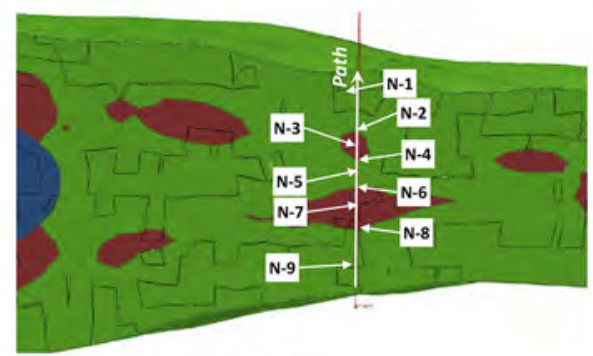

(c)

Figure 24 .

Cross-sectional cuts through each location from point $\mathrm{B}$ to $\mathrm{G}$ and illustration of the vertical paths and node location for point B. (green tissue, red - primary cartilage, blue secondary cartilage)

coordinate system. Figure 25 shows a top view of the location of the specific primary cartilage for this discussion. The figure also shows the reference local axes with the global coordinate system and the location of each of the cut sections in Figure 24. Similar to the previously discussed locations (center and point A), nodes were selected at the tissue region inside the cartilages and at the interface between the tissue and cartilage. The list of the nodes and their location using Figure 24 as reference is presented in Table II. Paths along points $\mathrm{B}$ and $\mathrm{C}$ are crossing only one primary cartilage, thus each section has six nodes through the thickness. The path along point $\mathrm{D}$ goes through two cartilages, thus having nine nodes through the thickness.

The von Mises stresses and $\sigma_{X}^{\prime}$ along each cartilage local $x$-axis are reported in Figures 26 and 27, respectively. Similar to results from point A, this is a region where most

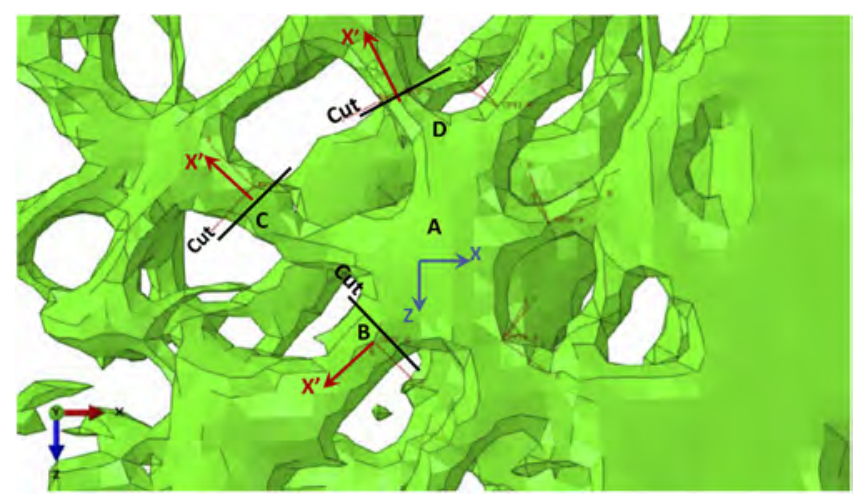

Figure 25.

References of local axes of selected primary cartilages $(b$, c and d) 
of the yielding is occurring. The figure marks the applied pressure where the section starts to yield. Higher stresses are observed in the direction of the global $x$-axis as opposed to the center of the rostrum where larger values of stress occur along the global $z$-axis. The von Mises stresses in Figure 26 indicate that outermost selected nodes reach yielding at applied pressures between 15 and $20 \mathrm{MPa}(2.18$ and $2.90 \mathrm{ksi})$. Nodes close to the neutral axis did not reach yielding except in point B [Figure 25(a)] where N-5 reach yield values after the applied load of $23 \mathrm{MPa}$ (3.34 ksi).

Figure 25 shows the stresses along a local $x$-axis in the direction of the cartilage. Because the material is all steel, the stresses along this direction are not necessarily stresses that are

\section{Table II.}

Reference nodes locations at cross section

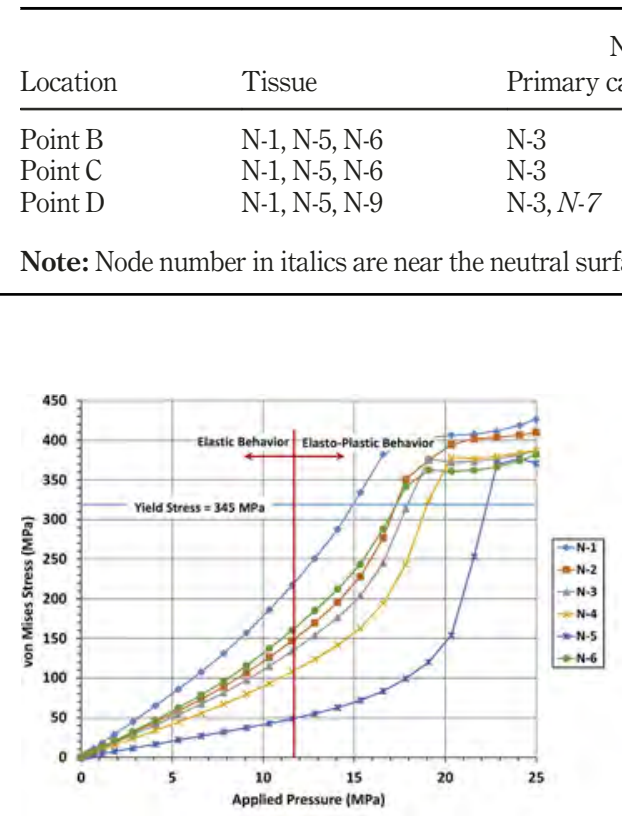

(a)

Note: Node number in italics are near the neutral surface

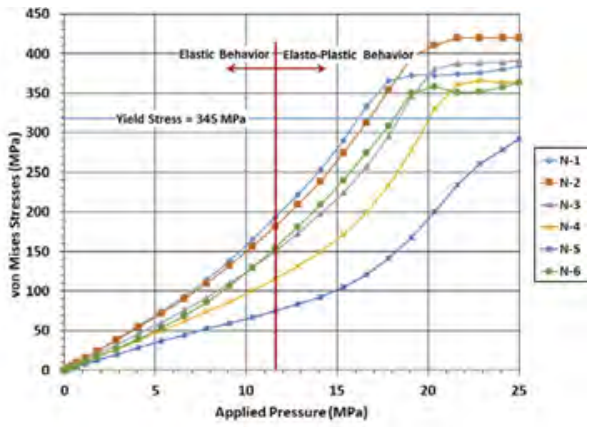

(b)
Figure 26.

von Mises stresses of the nodes along the cross sections shown in Figure 22
Nodes per component

Tissue/primary cartilage boundary

N-2, N-4

$\mathrm{N}-2, \mathrm{~N}-4$

N-2, N-4, N-6, N-8

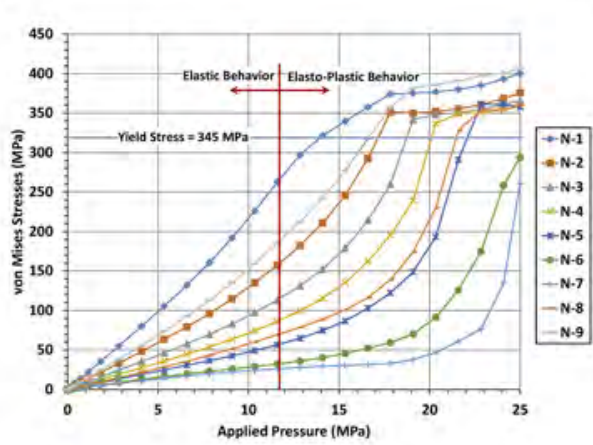

(c)

Notes: (a) Point B; (b) point C; (c) point D 


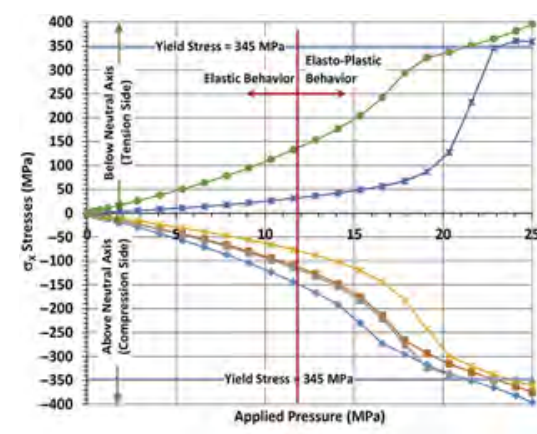

(a)

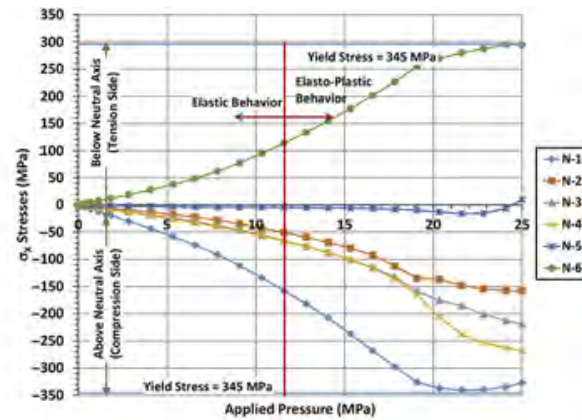

(b)

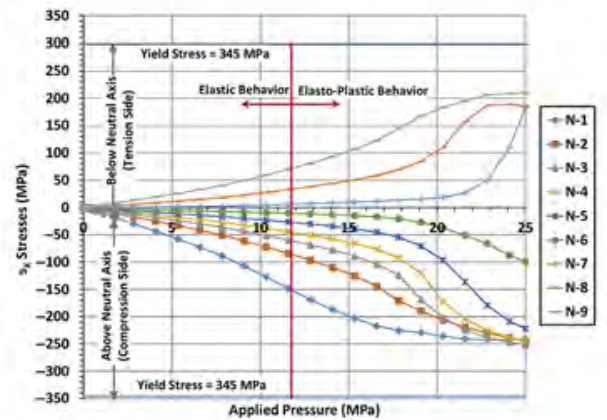

(c)

Notes: (a) Point B; (b) point C; (c) point D

Figure 27.

Stresses along the local $x$-axis $\left(\sigma_{x}^{\prime}\right)$ of the nodes along the cross sections shown in Figure 22

transferred through the direction of the cartilage. Depending on the relative orientation of the local $x$-axis with respect to the global $x$ - and $y$-axes, it is the level of yielding observed along this direction. If the local $x$-axis is closer to the global $x$-axis, the section will show higher levels of yielding [Figure 25(a) and (b)] as opposed to section with the local $x$-axis closer to the global $z$-axis [Figure 27(c)] that show no yielding.

\section{Mechanism of load transfer concluding remarks}

Results provide an initial phase where the maximum stresses are localized in the intersection of the lattice architecture members and the center bone. This is not just necessary, but essential to design a bioinspired walls. Deformations provide a level of ductility and energy dissipation characteristics for this structural system. Additionally, it will be feasible to understand the benefits of using a combination of different materials to optimize an effective use of materials on the bioinspired geometrical system.

\section{Conclusions}

This article presents a comparison of four finite element models of a paddlefish rostrum generated from tomographic scan images. The models considered first-order (linear) elements and second-order (quadratic) elements with reduced and full integration scheme to generate the element stiffness matrices. The material used was steel, 
considering elastic-plastic behavior. All models were fixed supported at the rostrum edges and loaded by self-weight and gradually to a maximum applied pressure of $25 \mathrm{MPa}(3.63 \mathrm{ksi})$. The models were imported into the commercial software ABAQUS and executed using parallel processing capabilities of the ERDC high performing computing facilities.

The literature has general suggestions regarding the general applications of each type of element and integration order. However, selection of the right mesh is problem dependent. From this parametric study, it is concluded the following:

- There is no significant difference between integration orders for similar type of elements (first order or quadratic). This can be attributed to the fact that only hexahedral (brick) elements can have reduced integration orders. Because the models are predominately tetrahedral elements (91.5 per cent), they dominate the global model behavior.

- Second-order elements are, in general, more accurate than first-order elements. However, this model does not have experimental data but have been validated against a bioinspired panel which showed same deformation patterns as the paddlefish rostrum. It is concluded that second-order elements with reduced integration are the alternative to analyze biological structures. They can better adapt to the complex natural contours and can model accurately stress concentrations and distributions without over stiffening their general response.

- A drawback to use second-order elements is the increase in computational time and result manipulation, but it can be overcome using modern computing facilities.

The non-uniform geometry of the rostrum creates an interesting behavior when loaded as a fixed plate. The section that connects to the fish is narrower and stiff. The section away from the fish is flat and thinner. The stress curves of the zone away from the center cartilage show behavior as plates at the materials' linear range. However at some regions, the curves show nonproportional behavior due to the geometrical nonlinearity of the section. Finally, mesh imperfections created during mesh generation caused irregular stress curves when the elements are change from first order to second order.

\section{References}

ABAQUS (2014), ABAQUS Documentation, Dassault Systèmes, Providence, RI.

Alam, P., Amini, S., Tadayon, M., Miserez, A. and Chinsamy, A. (2016), "Properties and architecture of the sperm whale skull amphitheatre”, Zoology, Vol. 119 No. 1, pp. $42-51$.

Allen, J.B. and Riveros, G.A. (2013), "Hydrodynamic characterization of the Polyodon spathula rostrum using CFP", Journal of Applied Mathematics, p. 8.

Allison, P.G., Deang, J.F., Diaz, A.J., Poda, A.R., Hoover, J.J., Horstemeyer, M.F. and Perkins, E.J. (2013), "Characterization of paddlefish (Polyodon spathula) rostrum stellate bones", Bioinspired, Biomimetic and Nanobiomaterials, Vol. 3 No. 1, pp. 63-68.

Allison, P.G., Chandler, M.Q., Rodriguez, R.I., Williams, B.A., Moser, R.D., Weiss, C.A., Jr, Poda, A.R., Lafferty, B.J., Kennedy, A.J., Seiter, J.M., Hodo, W.D. and Cook, R.F. (2013), "Mechanical properties and structure of the biological multilayered material system, atractosteus spatula scales", Acta Biomaterialia, Vol. 9 No. 2, pp. 5289-5296.

Benzley, S.E., Perry, E., Merkley, K. and Clark, B. (1995), "A comparison of al hexagonal and all tetrahedral finite element meshes for elastic and Elasto-Plastic analysis", Proceedings of the 4th International Meshing Roundtable, Sandia National Laboratories, pp. 179-191. 
de Oliveira, B.L. and Sundnes, J. (2016), "Comparison ofTetrahedral and hexahedral meshes for finite element simulation of cardiac Electro-Mechanics", in Papadrakakis, M., Papadopoulos, V., Stefanou, G. and Plevris V. (Eds), Proceedings of the VII European Congress on Computational Methods in Applied Sciences and Engineering, p. 14.

Deang, J.F., Allison, P.G., Prabhu, R., Williams, L.N., Rhee, H., Whittington, W.R., Perkins, E.J., Bruce, S.M. and Horstemeyer, M.F. (2017), "Constitutive behaviour of paddlefish (Polyodon spathula) cartilage", Bioinspired, Biomimetic and Nanobiomaterials, Vol. 6 No. 4, pp. 1-8.

Flammang, B.E. and Porter, M.E. (2011), "Bioinspiration: applying mechanical design to experimental biology", Integrative and Comparative Biology, Vol. 51 No. 1, pp. 128-132.

Flores-Johnson, E., Shen, L., Guiamatsia, I. and Nguyen, G.D. (2014), "Numerical investigation of the impact behavior of bioinspired nacre-like aluminum composite plates", Composites Science and Technology, Vol. 96, pp. 13-22.

Flores-Johnson, E., Shen, L., Guiamatsia, I. and Nguyen, G.D. (2015), “A numerical study of bioinspired nacre-like composite plates under blast loading”, Composite Structures, Vol. 126, pp. 329-336.

Forbes, S.A. (1878), "The food of Illinois fishes", Bulletin of the Illinois State Laboratory of Natural History, Vol. 1, pp. 71-89.

Forbes, S.A. (1888a), "Studies of the food of freshwater fishes", Illinois Natural History Survey Bulletin, Vol. 2 No. 7, pp. 433-473.

Forbes, S.A. (1888b), "On the food relations of freshwater fishes: a summary and discussion", Illinois Natural History Survey Bulletin, Vol. 2 No. 8, pp. 475-538.

Gurgens, C., Russell, D.F. and Wilkens, L.A. (2000), "Electrosensory avoidance of metal obstacles by the paddlefish", Journal of Fish Biology, Vol. 57 No. 2, pp. 277-290.

Hoover, J., Perkins, E. and Allison, P. (2013a), "Structural and material properties of the paddlefish rostrum", Proceedings to Technical Directors, US Army Engineer Research and Development Center, Vicksburg, MS, February 2013.

Hoover, J.J., Rayfield, N., Allison, P.G., Riveros, G., Patel, R.R. and Perkins, E. (2013b), "Role of the rostrum in Swimming performance of Juvenile Paddlefish (Polyodon spathula)" Proceedings of the American Fisheries Society 143rd Annual Meeting.

Hughes, T.R. and Belytschko, T. (2002), "Nonlinear finite element analysis", A short course taught by Thomas J.R. Hughes and Ted Belytschko.

Knipprath, C., Bond, I. and Trask, R. (2012), "Biologically inspired crack delocalization in a high strainrate environment", Journal of the Royal Society Interface, Vol. 9 No. 69, pp. 665-676.

Liu, Y. and Glass, G. (2013), "Effects of mesh density on finite element analysis", Proceedings of the SAE 2013 World Congress and Exhibition.

Lubliner, J. (1990), Plasticity Theory, Macmillan Publishing Company, New York, NY.

Patel, R. (2018), "Complex network analysis for early detection of failure mechanisms in resilient biostructures", PhD Dissertation, Mississippi State University, Starkville.

Patel, R.R. and Riveros, G.A. (2013), "Towards development of innovative Bio-Inspired materials by analyzing the hydrodynamic properties of Polyodon spathula (paddlefish) rostrum", Technical Report ERDC/ITL TR-13-4, US Army Corps of Engineers, Washington, DC.

Pothmann, L., Wilkens, L.A. and Hofmann, M.H. (2012), "Two modes of information processing in the electrosensory system of the paddlefish (Polyodon spathula)", Journal of Comparative Physiology A, Vol. 198 No. 1, pp. 1-10.

Riveros, G.A., Patel, R.R. and Hoover, J.J. (2014), "Swimming and energy dissipation enhancement induced by the rostrum of the paddlefish (Polyodon spathula): a multiphysics, fluid-structure interaction analysis", Materials Research Society Fall Meeting.

Riveros, G.A., Patel, R.R., Hoover, J.J., Hodo, W. and Acosta, F.J. (2014), "Swimming and energy dissipation enhancement induced by the rostrum of the paddlefish (Polyodon spathula): a 
multiphysics, Fluid-Structure interaction analysis", AfichePresentadoen la Conferencia Materials Research Society Fall Meeting.

Snively, E.D., Fahlke, J.M. and Welsh, R.C. (2015), "Bone-breaking bite force of basilosaurusisis (mammalia, cetacea) from the late eocene of Egypt estimated by finite element analysis", Plos One, Vol. 10 No. 2.

Synopsys (2017), "Simpleware converting 3D images into models", available at: www.simpleware.com (accessed 16 April 2017).

Tran, P., Ngo, T.D. and Mendis, P. (2014), "Bio-inspired composite structures subjected to under water impulsive loading”, Computational Materials Science, Vol. 82, pp. 134-139.

Tsukrov, I., DeCew, J., Baldwin, K., Campbell-Malone, R. and Moore, M. (2009), "Mechanics of the right whale mandible: full scale testing and finite element analysis", Journal of Experimental Marine Biology and Ecology, Vol. 374 No. 2.

Vepari, C. and Kaplan, D.L. (2007), "Silk as biomaterial”, Progress in Polymer Science, Vol. 32 Nos 8/9, pp. 991-1007.

Wilkens, L.A. and Hofmann, M.H. (2007), "The paddlefish rostrum as an electrosensory organ: a novel adaptation for plankton feeding”, BioScience, Vol. 57 No. 5, pp. 399-407.

Wilkens, L.A., Hofmannb, M.H. and Wojteneka, W. (2002), "The electric sense of the paddlefish: a passive system for the detection and capture of zooplankton prey", Journal of Physiology-Paris, Vol. 96 Nos 5/6, pp. 363-377.

\section{Further reading}

Acosta, F.J., Riveros, G.A., Patel, R.R. and Hodo, W. (2017), "Numerical simulation of biological structures: Paddlefish rostrum", Technical Report ERDC/ITL TR-19-7, US Army Corps of Engineers, Washington, $D C$.

Sen, D. (2011), "Improvement in mechanical properties through structural hierarchies in bio-inspired materials", Dissertation Massachusetts Institute of Technology.

\section{Corresponding author}

Guillermo A. Riveros can be contacted at: guillermo.a.riveros@usace.army.mil 


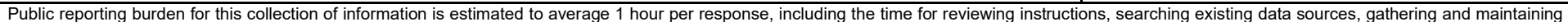

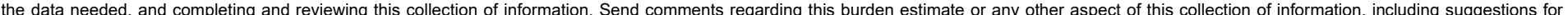

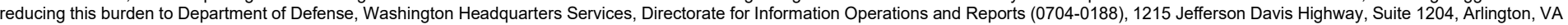

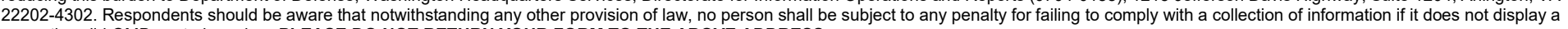
currently valid OMB control number. PLEASE DO NOT RETURN YOUR FORM TO THE ABOVE ADDRESS.
1. REPORT DATE (DD-MM-YYYY)
September 2021
Final

4. TITLE AND SUBTITLE

Computational Mechanics of the Paddlefish Rostrum
3. DATES COVERED (From - To)

5a. CONTRACT NUMBER

5b. GRANT NUMBER

5c. PROGRAM ELEMENT NUMBER

5d. PROJECT NUMBER

5e. TASK NUMBER

5f. WORK UNIT NUMBER

8. PERFORMING ORGANIZATION REPORT NUMBER

ERDC MP-21-13

10. SPONSOR/MONITOR'S ACRONYM(S)

9. SPONSORING / MONITORING AGENCY NAME(S) AND ADDRESS(ES)

U.S. Army Corps of Engineers

Washington, DC 20314
11. SPONSOR/MONITOR'S REPORT NUMBER(S)

\section{DISTRIBUTION / AVAILABILITY STATEMENT}

Approved for public release; distribution is unlimited.

\section{SUPPLEMENTARY NOTES}

This article was originally published in Engineering Computations on 9 December 2019.

Financial support was provided by U.S. Army Engineer Research and Development Center (ERDC) under PE 0601102 , Project T22

"Research in Soil and Rock Mechanics," Task 01, and, also with support and resources from the ERDC Department of Defense

Supercomputing Resource Center (ERDC DSRC) under the subproject of environmental quality modeling and simulation.

\section{ABSTRACT}

Purpose - The rostrum of a paddlefish provides hydrodynamic stability during feeding process in addition to detect the food using receptors that are randomly distributed in the rostrum. The exterior tissue of the rostrum covers the cartilage that surrounds the bones forming interlocking star shaped bones.

Design/methodology/approach - The aim of this work is to assess the mechanical behavior of four finite element models varying the type of formulation as follows: linear-reduced integration, linear-full integration, quadratic-reduced integration and quadratic-full integration. Also presented is the load transfer mechanisms of the bone structure of the rostrum.

Findings - Conclusions are based on comparison among the four models. There is no significant difference between integration orders for similar type of elements. Quadratic-reduced integration formulation resulted in lower structural stiffness compared with linear formulation as seen by higher displacements and stresses than using linearly formulated elements. It is concluded that second-order elements with reduced integration and can model accurately stress concentrations and distributions without over stiffening their general response.

\section{SUBJECT TERMS}

Finite elements, Energy dissipation, Bioinspiration, Paddlefish, Rostrum

16. SECURITY CLASSIFICATION OF:

\section{a. REPORT}

Unclassified

\section{b. ABSTRACT}

Unclassified c. THIS PAGE

Unclassified
17. LIMITATION OF ABSTRACT

UU
18. NUMBER OF PAGES

30 19a. NAME OF RESPONSIBLE PERSON

19b. TELEPHONE NUMBER (include area code) 
Information Technology Laboratory

US Army Engineer Research and Development Center 3909 Halls Ferry Road

Vicksburg, MS 39180

Department of Civil Engineering and Surveying University of Puerto Rico

Mayaguez, Puerto Rico

Geotechnical and Structures Laboratory

US Army Engineer Research and Development Center 3909 Halls Ferry Road

Vicksburg, MS 39180 